\title{
Research Article:
}

\section{The Effect of Resistance Training with Theraband on the Transforming Growth Factor- $\beta$ in the Elderly Women}

\author{
Parisa Rajabi $^{1}$ (D, Amin Isanejad ${ }^{1 *}$ (D), Ali Samadi' ${ }^{\text {(D) }}$, Hamid Amini' ${ }^{1}$ (D)
}

1. Department of Physical Education \& Sport Sciences, Faculty of Humanities, Shahed University, Tehran, Iran.

Citation Rajabi P, Isanejad A, Samadi A, Amini H. The Effect of Resistance Training with Theraband on the Transforming Growth Factor- $\beta$ in the Elderly Women. Immunoregulation. 2019; 1(2):81-86. http://dx.doi.org/10.32598/Immunoregulation.1.2.75

http://dx.doi.org/10.32598/Immunoregulation.1.2.75

Funding: See Page 84

(c) Copyright: The Author(s)

Article info:

Received: 05 October 2017

Accepted: 28 February 2018

Available Online: 01 Jan 2019

Keywords:

Aging, Resistance

training, Elastic bands,

TGF- $\beta$, Women

\begin{abstract}
A B S T R A C T
Background: Ageing and physical inactivity can negatively affect immune system. On the contrary, a healthy lifestyle and physical activity can improve immune system and prevent from mild inflammatory diseases. Transforming Growth Factor- $\beta$ (TGF- $\beta$ ) can play an important role in the regulation of immune function and inflammation. This study aimed to investigate the effects of 8 weeks of theraband resistance training on the plasma level of TGF- $\beta$ in the elderly women.
\end{abstract}

Materials and Methods: Eighteen inactive elderly women were selected and randomly assigned to either theraband $(\mathrm{n}=10)$ and control $(\mathrm{n}=8)$ groups. The theraband group attended 24 exercise sessions conducted over an 8-week period (3 sessions/week). Exercise load was increased according to the color of theraband. The TGF- $\beta$ level in plasma was measured by ELISA.

Results: Mean \pm SD in plasma level of TGF- $\beta$ in the theraband group (39.42 \pm 9.46$)$ significantly decreased compared to that in the control group (64.26 \pm 21.39$)(\mathrm{P}=0.031)$

Conclusion: The results showed that lower level of TGF- $\beta$ and improvement of immune system following resistance training may (at least partially) protect the elderly women against infectious and inflammatory diseases.

\section{Introduction}

I

$\mathrm{n}$ the contemporary world with the huge advances in science and technology, especially the health sciences, the elderly people as a class of the society, are a growing population with special needs. According to 2013 $\mathrm{UN}$ report, about 841 million of world population were over 65 years old [1]. Aging changes occur in all body cells, tissues, organs, and systems including cardiovascular, musculoskeletal, and immune system. One of the most recognized consequences of aging is decline in immune system. Both innate and acquired immunity are affected by aging [2].

It is well known that immunological changes by aging can increase the risk of infectious diseases in elderly people $[3,4]$. TGF- $\beta$ is a pleiotropic cytokine

\section{* Corresponding Author:}

Amin Isanejad, PhD

Address: Department of Physical Education \& Sport Sciences, Faculty of Humanities, Shahed University, Tehran, Iran.

Phone: +98 (21) 51212456

E-mail: a.isanezhad@shahed.ac.ir 
with potent regulatory and inflammatory activity that contributes to many cellular functions, including the control of growth, regeneration, proliferation, differentiation, apoptosis and extracellular matrix deposition $[5,6]$. Higher level of TGF- $\beta$ is associated with obesity, insulin sensitivity deficiency, cardiovascular diseases, type 2 diabetes, and ageing [7-10].

Also, mutations in TGF- $\beta$ and its receptors are related to pathogenesis of autoimmune disorders of joints, especially cancer and inflammation [7]. TGF- $\beta$ can also suppress Natural Killer cells (NK), macrophages, dendritic cells, $\mathrm{T}$ helper lymphocytes, and proliferation of $\mathrm{B}$ cells, therefore impairs immune function against pathogens and accelerates the process of developing the disease $[6,11]$. Based on the evidence, TGF- $\beta$ is higher in older people [12]. The higher level of TGF$\beta$ has recently been demonstrated to play an important role in development of osteoarthritis [13] and muscle atrophy [14] in older people.

Regular physical activity can increase life expectancy and reduce risk factors of cardiovascular disease, diabetes, metabolic syndrome, hypertension, infectious diseases and cancer, and immune aging [2, 15, 16]. Physical activity also provides an opportunity for older people to have an active and independent life, to reduce disability and to improve their quality of life [17]. Studies have shown that different exercise training mods, for example resistance and endurance exercises, have positive effects on the static and dynamic balance, reaction time and strength of the elderly $[18,19]$. Some evidence suggests that resistance training with elastic bands increases functional performance and improves muscle mass in older people [20-22]. Furthermore, exercise training reduces low grade inflammation in both young and aged people $[23,24]$.

Bandeen-Roche et al. (2009) believed that the systemic inflammation was related to the reduced functional ability in older people [25]. In this regard, Schober-Halper et al. (2016) reported that 6 months of elastic band resistance training positively affected TGF- $\beta$ signaling in Peripheral Blood Mononuclear Cell (PBMC) through altered TGF- $\beta$ RI mRNA expression in older people [21].
In light of these facts, this study aimed to investigate the effect of 8 weeks resistance exercise with theraband on plasma TGF- $\beta$ level of elderly women.

\section{Materials and Methods}

\section{Participations and instruments}

A total of 26 eligible elderly women were selected and randomly assigned to resistance training group (theraband) $(n=18)$ or control group $(n=8)$. During the intervention, 8 women of resistance training group left the study because of loss of interest or acute medical reasons. The nature, objectives and possible risks of the study were explained to all participations and written consent was obtained from them. The inclusion criteria were as follows: non-participation in any designed physical exercise training program during the past 6 months, no cardiovascular disease, diabetes, cancer as well as infectious diseases during the implementation of the exercise protocol.

The exclusion criteria were inability to perform basic activities of daily living and smoking. The blood samples were taken from the participants in the fasting status (between 7 and 9 AM) before the study and after 8 weeks training period. Because of the effects of last exercise session, the second blood sample collected 48 hours after the last exercise session. The heparinized blood samples were centrifuged at $3000 \mathrm{rpm}$ at $4{ }^{\circ} \mathrm{C}$ for $15 \mathrm{~min}$ and then the plasma was collected and stored locally at $-80^{\circ} \mathrm{C}$ until further analysis. The plasma TGF- $\beta$ level was measured in duplicate using ELISA according to manufacturer's instructions (R\&D system USA). The sensitivity and intra CV of kit were 3-5 pg/mL and $4 \%-6 \%$, respectively. General characteristics of the participations are shown in Table 1.

\section{Resistance exercise training}

The progressive resistance exercise program with elastic band (Theraband) designed according to the American College of Sport Medicine (ACSM) guidelines. In this study, theraband used to perform resistant exercise. In the first step, the participants got familiar with elastic

Table 1. General characteristics of study participants

\begin{tabular}{cccc}
\hline Groups & Age, $\mathbf{y}$ & Height, $\mathbf{c m}$ & Weight, $\mathbf{k g}$ \\
\hline Exercise & $76.8 \pm 5.75$ & $153 \pm 6.49$ & $58.6 \pm 7.67$ \\
Control & $78.88 \pm 11.09$ & $150 \pm 6.8$ & $48.55 \pm 4.69$ \\
\hline
\end{tabular}

The data are presented as Mean \pm SD.

IminunoRegulatiov 
Table 2. Training program

\begin{tabular}{|c|c|c|c|c|c|c|}
\hline Week & Sets & Repetition & $\begin{array}{l}\text { Rest Between } \\
\text { Sets (Second) }\end{array}$ & $\begin{array}{l}\text { Rest Between Move- } \\
\text { ments (Second) }\end{array}$ & Intensity & Length of Theraband \\
\hline 1 & 1 & 10 & - & 2 & \multirow{8}{*}{$\begin{array}{l}\text { Start theraband colors with } \\
\text { rating of } 5 \text { on the OMNI-RES } \\
\text { scale and gradually reached to } \\
\text { rating of } 8 \text { on the OMNI-RES } \\
\text { scale. }\end{array}$} & \multirow{8}{*}{$\begin{array}{l}\text { It varies according to the type } \\
\text { of movement. }\end{array}$} \\
\hline 2 & 2 & 10 & 90 & $2-3$ & & \\
\hline 3 & 3 & 10 & 75 & $2-3$ & & \\
\hline 4 & 3 & 12 & 75 & $2-3$ & & \\
\hline 5 & 4 & 12 & 60 & $2-2.50$ & & \\
\hline 6 & 4 & 12 & 60 & $2-2.50$ & & \\
\hline 7 & 4 & 14 & 60 & 2 & & \\
\hline 8 & 4 & 14 & 60 & 2 & & \\
\hline
\end{tabular}

IMMUNoREGULATION

bands. The OMNI scale was used to determine the color of the theraband for each subject (this perceived exertion scale includes numerical categories from 0 to 10) and the desired intensity of the exercise were within 5-8 on a 10-point perceived exertion scale [26].

The subjects of theraband group performed resistance exercise for 8 weeks (three non-consecutive days per week). The duration of each session was about 45-50 min. Every exercise session was preceded by general and specific warm-up (10 min). Theraband resistance trainings included upper extremity exercises (shoulder press, scapular elevation, chest press, biceps cruel, shoulder abduction, shoulder adduction) and lower extremity exercises (hip abduction, leg press, hip flexion and plantar flexion) (Table 2). The control group continue their dayto-day activities during the study protocol.

\section{Statistical analyses}

The data are expressed as mean \pm standard deviation (Mean \pm SD). One-way ANCOVA was performed to determine the effect of theraband training whilst pretest data were considered as covariate. Levene's test and normality checks were carried out that satisfied the assump- tions. All statistical calculations were performed using SPSS V. 24. $\mathrm{P} \leq 0.05$ were set significant level.

\section{Results}

The plasma TGF- $\beta$ level significantly decreased after 8 weeks of theraband training (Figure 1). There was a significant difference between two groups regarding the mean plasma TGF- $\beta$ level $\left(\mathrm{F}_{2,16}=5.68, \mathrm{P}=0.031\right)$ (Table 3$)$.

\section{Discussion}

The current study aimed to investigate the effects of resistance training with elastic bands (Theraband) on plasma TGF- $\beta$ level in older women. Based on the results, the plasma TGF- $\beta$ level in the theraband group significantly reduced. Based on the evidence, endurance and strength exercise training alleviate the inflammation $[27$, 28 ]. Body fat tissue particularly visceral depots is one of the main sources of inflammatory cytokines such as IL-6 and TGF- $\beta$, thus exercise training by reducing body fat can influence inflammatory status [29]. Resistance training affects body composition by increasing muscle mass and decreasing body fat in older adults [30]. Therefore,

Table 3. The ANCOVA results

\begin{tabular}{|c|c|c|c|c|c|}
\hline Source of Changes & Type III Sum of Squares & df & Mean Squares & $\mathbf{F}$ & Sig. \\
\hline Corrected model & 5092.61 & 2 & 2546.305 & 23.02 & 0.000 \\
\hline Baseline TGF- $\beta$ & 2350.312 & 1 & 2350.312 & 21.24 & 0.000 \\
\hline Group & 628.893 & 1 & 628.893 & 5.68 & 0.031 \\
\hline
\end{tabular}




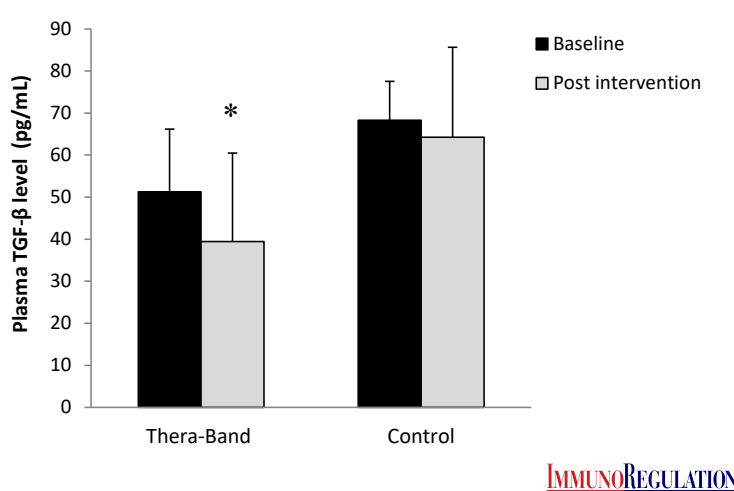

1. The plasma TGF- $\beta$ level at baseline and after 8 weeks of resistance training

it has been proposed that resistance training may exert anti-inflammatory effects [21].

In contrast to our results, Bautmans et al. (2005) did not show any significant changes in circulatory level TGF- $\beta$ of by intensive resistance exercise training in the elderly [31]. As we know moderate exercise training could improve immune function and reduce inflammation [24], thus different intensity may influence the inflammatory markers. In this study, we used moderate intensity resistance training. Schober et al. (2016) reported that 3 months of resistance training with elastic band had no significant effect on TGF- $\beta$, as well as gene expression of TGF- $\beta$ in the elderly people. However, the mRNA expression of TGF- $\beta$ receptor, TGF- $\beta$, significantly decreased. They concluded that due to the reduced expression of TGF- $\beta$ receptor in mononuclear cells, this kind of exercise training seems to reduce the TGF- $\beta$ messenger [21].

On the contrary, Hering et al. (2002) reported that 4 weeks of intense stretching exercise $(5 \mathrm{~d} / \mathrm{wk}$; each session for120 $\mathrm{min}$ ) resulted in a significant decrease in TGF- $\beta$ plasma and serum level in young men. However, TGF- $\beta$ increased in the second week, which could be due to acute mechanical stimuli and osteoid stimulation, resulting in a negligible release of TGF- $\beta$ from the bone matrix. In the third and fourth weeks, TGF- $\beta$ level decreased, which could indicate mechanical stimulus adaptation. Furthermore, it has been known that TGF- $\beta$ family such as myostatin is a stimulating factor in atrophy, and inhibitory factor in muscle hypertrophy [32]. Chronic inflammation is one of the reasons of muscle mass losing by aging (sarcopenia). Therefore resistance training by decreasing TGF- $\beta$ may prevent the sarcopenia in the elderly $[33,34]$. However we did not measure the mass muscle of the study participations. The exercise by stimulating muscular adaptation (increased muscle mass, cross-sectional, and strength) leads to muscle atrophy [35]. In fact, exercise training by reducing fat mass and increasing cardiovascular fitness, regulates the factors associated with the immune system.

In summary, this study has established the effect of resistance exercise with theraband on plasma levels of TGF- $\beta$ in the elderly women. Our results suggest that lower levels of TGF- $\beta$ and improvement of immune system may (at least partially) protect elderly women against infectious and inflammatory diseases as well as sarcopenia. The present results indicate that lower levels of TGF- $\beta$ and improvement of immune system following resistance training may, at least partially, protect elderly women against infectious and inflammatory diseases.

\section{Ethical Considerations}

\section{Compliance with ethical guidelines}

All study activities were reviewed and approved by the Medical Ethics Committee of the Shahed University (No: IR.SHAHED.REC.1395).

\section{Funding}

This work was supported by Shahed University.

\section{Conflict of interest}

The authors of the manuscript have no conflict of interest to declare and are responsible for the content of the paper.

\section{Acknowledgements}

We thank the patients, families, and the study staff for their participation in the study.

\section{Reference}

[1] United Nations. World population ageing 2013. New York United Nations; 2013.

[2] Massoud A, Rezaei N. Immunology of aging. Berlin: Springer; 2014. [DOI:10.1007/978-3-642-39495-9]

[3] Pawelec G, Goldeck D, Derhovanessian E. Inflammation, ageing and chronic disease. Current Opinion in Immunology. 2014; 29:23-8. [DOI:10.1016/j.coi.2014.03.007] [PMID]

[4] Pera A, Campos C, López N, Hassouneh F, Alonso C, Tarazona R, et al. Immunosenescence: Implications for response to infection and vaccination in older people. Maturitas. 2015 82(1):50-5. [DOI:10.1016/j.maturitas.2015.05.004] [PMID] 
[5] Gumucio JP, Sugg KB, Mendias CL. Mendias, TGF- $\beta$ superfamily signaling in muscle and tendon adaptation to resistance exercise. Exercise and Sport Sciences Reviews. 2015; 43(2):939. [DOI:10.1249/JES.0000000000000041] [PMID] [PMCID]

[6] Travis MA, Sheppard D. Sheppard, TGF- $\beta$ activation and function in immunity. Annual Review of Immunology. 2014; 32(1):51-82. [DOI:10.1146/annurev-immunol-032713-120257] [PMID] [PMCID]

[7] Romano M, Guagnano MT, Pacini G, Vigneri S, Falco A, Marinopiccoli M, et al. Association of inflammation markers with impaired insulin sensitivity and coagulative activation in obese healthy women. The Journal of Clinical Endocrinology \& Metabolism. 2003; 88(11):5321-6. [DOI:10.1210/ jc.2003-030508] [PMID]

[8] Agarwal I, Glazer NL, Barasch E, Biggs ML, Djousse L, Fitzpatrick AL, et al. Fibrosis-related biomarkers and incident cardiovascular disease in older adults: the cardiovascular health study. Circulation: Arrhythmia and Electrophysiology. 2014; 7(4):5839. [DOI:10.1161/CIRCEP.114.001610.] [PMID] [PMCID]

[9] Pfeiffer A, Middelberg-Bisping K, Drewes C, Schatz H. Elevated plasma levels of transforming growth factor- $\beta 1$ in NIDDM. Diabetes Care. 1996; 19(10):1113-7. [DOI:10.2337/ diacare.19.10.1113] [PMID]

[10] Lin Y, Nakachi K, Ito Y, Kikuchi S, Tamakoshi A, Yagyu K, et al. Variations in serum transforming growth factor- $\beta 1$ levels with gender, age and lifestyle factors of healthy Japanese adults. Disease Markers. 2009; 27(1):23-8. [DOI:10.1155/2009/529253] [PMID] [PMCID]

[11] Sheng J, Chen W, Zhu HJ. The immune suppressive function of transforming growth factor- $\beta$ (TGF- $\beta$ ) in human diseases. Growth Factors. 2015; 33(2):92-101. [DOI:10.3109/089 77194.2015.1010645] [PMID]

[12] Forsey RJ, Thompson JM, Ernerudh J, Hurst TL, Strindhall J, Johansson B, et al. Plasma cytokine profiles in elderly humans. Mechanisms of Ageing and Development. 2003; 124(4):487-93. [DOI:10.1016/S0047-6374(03)00025-3]

[13] Van der Kraan PM, Goumans MJ, Blaney Davidson E, ten Dijke P. Age-dependent alteration of TGF- $\beta$ signalling in osteoarthritis. Cell and Tissue Research. 2011; 347(1):257-65. [DOI:10.1007/s00441-011-1194-6] [PMID] [PMCID]

[14] Glass DJ. PI3 kinase regulation of skeletal muscle hypertrophy and atrophy. Phosphoinositide 3-Kinase in Health and Disease. 2010; 267-78. [DOI:10.1007/82_2010_78] [PMID]

[15] Justine M, Hamid TA, Mohan V, Jagannathan M. Effects of multicomponent exercise training on physical functioning among institutionalized elderly. ISRN Rehabilitation. 2012; 2012:1-7.

[16] Kendall KL, Fairman CM. Women and exercise in aging. Journal of Sport and Health Science. 2014; 3(3):170-8. [DOI:10.1016/j.jshs.2014.02.001]

[17] Chodzko-Zajko WJ. The World Health Organization issues guidelines for promoting physical activity among older persons. Journal of Aging and Physical Activity. 1997; 5(1):1-8. [DOI:10.1123/japa.5.1.1]

[18] Ghasempour L, Hoseini F S, Soleymani M, Ahmadi M. [Effects of physical fitness exercise, mental exercise and mindfulness exercise on static and dynamic balance in elderly women (Persian)]. Iranian Journal of Ageing. 2017; 12(2):180-91. [DOI:10.21859/sija-1202180]
[19] Touvra AM, Volaklis K, Spassis A, Zois C, Douda H, Kotsa $\mathrm{K}$, et al. Combined strength and aerobic training increases transforming growth factor- $\beta 1$ in patients with type 2 diabetes. Hormones. 2011; 10(2):125-30. [DOI:10.14310/horm.2002.1302]

[20] Oesen S, Halper B, Hofmann M, Jandrasits W, Franzke B, Strasser E-M, et al. Effects of elastic band resistance training and nutritional supplementation on physical performance of institutionalised elderly: A randomized controlled trial. Experimental Gerontology. 2015; 72:99-108. [DOI:10.1016/j. exger.2015.08.013] [PMID]

[21] Schober-Halper B, Hofmann M, Oesen S, Franzke B, Wolf $\mathrm{T}$, Strasser EM, et al. Elastic band resistance training influences transforming growth factor- $\mathrm{B}$ receptor I mRNA expression in peripheral mononuclear cells of institutionalised older adults: The Vienna Active Ageing Study (VAAS). Immunity \& Ageing. 2016; 13(1):22. [DOI:10.1186/s12979-0160077-9] [PMID] [PMCID]

[22] Hofmann M, Schober-Halper B, Oesen S, Franzke B, Tschan $\mathrm{H}$, Bachl N, et al. Effects of elastic band resistance training and nutritional supplementation on muscle quality and circulating muscle growth and degradation factors of institutionalized elderly women: The Vienna Active Ageing Study (VAAS). European Journal of Applied Physiology. 2016; 116(5):885-97. [DOI:10.1007/s00421-0163344-8] [PMID] [PMCID]

[23] Kohut ML, McCann DA, Russell DW, Konopka DN, Cunnick JE, Franke WD, et al. Aerobic exercise, but not flexibility/resistance exercise, reduces serum IL-18, CRP, and IL-6 independent of $\beta$-blockers, BMI, and psychosocial factors in older adults. Brain, Behavior, and Immunity. 2006; 20(3):2019. [DOI:10.1016/j.bbi.2005.12.002] [PMID]

[24] Gleeson M. Anti-inflammatory effects of exercise. Obesity, Inflammation and Cancer. 2013; 401-24. [DOI:10.1007/978-14614-6819-6_16]

[25] Bandeen-Roche K, Walston JD, Huang Y, Semba RD, Ferrucci $L$. Measuring systemic inflammatory regulation in older adults: Evidence and utility. Rejuvenation Research. 2009; 12(6):403-10. [DOI:10.1089/rej.2009.0883] [PMID] [PMCID]

[26] Colado JC, Garcia-Masso X, Triplett TN, Flandez J, Borreani S, Tella V. Concurrent validation of the OMNI-resistance exercise scale of perceived exertion with Thera-band resistance bands. The Journal of Strength \& Conditioning Research. 2012; 26(11):3018-24 [DOI:10.1519/JSC.0b013e318245c0c9] [PMID]

[27] Chupel MU, Direito F, Furtado GE, Minuzzi LG, Pedrosa FM, Colado JC, et al. Strength training decreases inflammation and increases cognition and physical fitness in older women with cognitive impairment. Frontiers in Physiology. 2017; 8:377. [DOI:10.3389/fphys.2017.00377] [PMID] [PMCID]

[28] Simpson RJ, Lowder TW, Spielmann G, Bigley AB, LaVoy EC, Kunz H. Exercise and the aging immune system. Ageing Research Reviews. 2012; 11(3):404-20. [DOI:10.1016/j. arr.2012.03.003] [PMID]

[29] Sallam N, Laher I. Exercise modulates oxidative stress and inflammation in aging and cardiovascular diseases. Oxidative Medicine and Cellular Longevity. 2016; 2016:1-32.

[30] Binder EF, Yarasheski KE, Steger-May K, Sinacore DR, Brown $\mathrm{M}$, Schechtman KB, et al. Effects of progressive resistance training on body composition in frail older adults: results 
of a randomized, controlled trial. The Journals of Gerontology Series A: Biological Sciences and Medical Sciences. 2005; 60(11):1425-31. [DOI:10.1093/gerona/60.11.1425] [PMID]

[31] Bautmans I, Njemini R, Vasseur S, Chabert H, Moens L, Demanet $C$, et al. Biochemical changes in response to intensive resistance exercise training in the elderly. Gerontology. 2005; 2005; 51(4):253-65. [DOI:10.1159/000085122] [PMID]

[32] Sandri M. Signaling in muscle atrophy and hypertrophy. Physiology. 2008; 23(3):160-70. [DOI:10.1152/physiol.00041.2007] [PMID]

[33] Roubenoff R. Catabolism of aging: Is it an inflammatory process. Current Opinion in Clinical Nutrition \& Metabolic Care. 2003; 6(3):295-9. [DOI:10.1097/01. mco.0000068965.34812.62] [PMID]

[34] Jensen GL. Inflammation: Roles in aging and sarcopenia. Journal of Parenteral and Enteral Nutrition. 2008; 32(6): 6569. [DOI:10.1177/0148607108324585] [PMID]

[35] Trappe S, Williamson D, Godard M, Porter D, Rowden G, Costill $\mathrm{D}$. Effect of resistance training on single muscle fiber contractile function in older men. Journal of Applied Physiology. 2000; 89(1):143-52. [DOI:10.1152/jappl.2000.89.1.143] [PMID] 